\title{
Comité de Publicaciones Médicas del Hospital Ángeles León: experiencia de cinco años
}

\author{
Medical Publications Committee of the Hospital \\ Ángeles León: five years' experience
}

Luis Gerardo Domínguez Carrillo*

En marzo de 2014, se constituyó el Comité de Publicaciones Médicas del Hospital Ángeles León (HAL), cuya misión es involucrar a los médicos de la institución en la elaboración de manuscritos con el fin de publicarlos. De esta manera, se cumple así uno de los objetivos primordiales que debe alcanzar el profesionista de la medicina, que es el de transmitir sus experiencias, siendo la publicación una manera de lograrlo. En el reporte inicial, se dieron a conocer las características del comité, sus lineamientos y los resultados obtenidos a un año de trabajo y, posteriormente al alcanzar la cifra de cien, se efectuó un segundo reporte de manuscritos. En esta ocasión, a cinco años de su formación, presentamos las experiencias durante la elaboración de los primeros 207 manuscritos de médicos del HAL, así como sus características y evolución.

Se revisaron los 207 manuscritos realizados por médicos del HAL, los cuales se clasificaron: a) por la característica del manuscrito (artículo original, de revisión, caso clínico, imagen en medicina, historia de la medicina); b) por su estatus al momento de la redacción de este reporte en: publicado, en prensa, en revisión, etc.; c) por nombre de la revista a la que se envió el manuscrito; d) por el número de médicos involucrados en la elaboración en relación con la cifra de médicos de la institución, anotando en las referencias bibliográficas los artículos publicados.

A cinco años de la formación del Comité de Publicaciones del HAL, sus acciones reportan la asesoría, revisión y corrección de 207 manuscritos. Éstos corresponden a la

\footnotetext{
* Especialista en Medicina de Rehabilitación. Coordinador del Comité de Publicaciones del Hospital Ángeles León (2014-2019). Catedrático de la Facultad de Medicina de León. Universidad de Guanajuato. México.
}

Correspondencia:

Acad. Dr. Luis Gerardo Domínguez Carrillo

Correo electrónico: Igdomínguez@hotmail.com

Aceptado: 02-10-2019.

www.medigraphic.com/actamedica

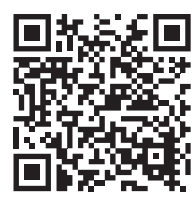

siguiente clasificación: 26 artículos originales, 11 de revisión, 68 de casos clínicos, 87 de imágenes en medicina, dos manuscritos de Historia de la Medicina, una Carta al Editor, un capítulo para el Libro de Medicina Interna y 10 Imágenes en Video (Tabla 1).

Los manuscritos se hicieron llegar a 24 publicaciones científicas (Tabla 2): 16 nacionales e indexadas en el portal Artemisa, las cuales son reconocidas por la Academia Nacional de Medicina de México, además de ocho revistas extranjeras.

De los 207 manuscritos realizados que se encuentran al cierre de este reporte, son: 170 artículos publicados y 27 artículos en prensa, haciendo un subtotal de 197 artículos aceptados, agregando 10 manuscritos actualmente en revisión por comités editoriales, lo que indica una producción de 3.18 manuscritos/mes durante los cinco años y cuatro meses de actividad (Figura 1). El Comité asesoró a 98 médicos (70\%) de la institución en su elaboración, además de 16 internos de pregrado.

Por parte del Comité, las acciones de asesoría reportan: la revisión de 207 documentos que incluyeron 1,243 páginas, 84 cuadros, 376 fotografías, 305 pies de gráficas o figuras y 1,895 referencias bibliográficas. Se efectuaron 250 entrevistas personales; 1,320 correos electrónicos;

Figura 1: Manuscritos de médicos del Hospital Ángeles León 2014-2019.

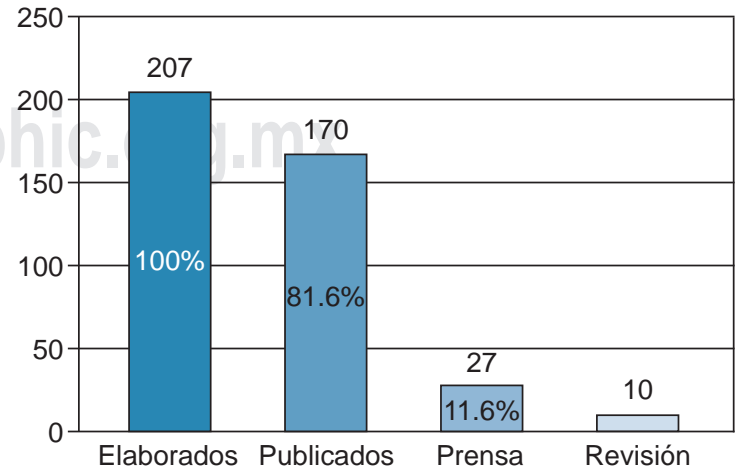


Tabla 1: Clasificación por tipo de manuscritos de médicos del Hospital Ángeles León.

$\begin{array}{lrr}\text { Tipo de manuscrito } & \text { Número } & \% \\ \text { Original } & 26 & 12.56 \\ \text { Revisión } & 11 & 5.31 \\ \text { Imagen en medicina } & 87 & 42.02 \\ \text { Imagen en video } & 10 & 4.83 \\ \text { Caso clínico } & 68 & 32.85 \\ \text { Historia de la medicina } & 2 & 0.96 \\ \text { Carta al editor } & 1 & 0.48 \\ \text { Capítulo en libro } & 1 & 0.48 \\ \text { Editorial } & 1 & 0.48 \\ \text { Total } & 207 & 100.00\end{array}$

305 Ilamadas telefónicas; apoyo en 58 modificaciones a manuscritos solicitadas por comités editoriales; presentación de 64 informes mensuales de las acciones del comité, así como cinco informes anuales y cuatro exposiciones de resultados en sesión general de la institución (dos de ellas formando parte de las sesiones del Capítulo Centro de la Academia Nacional de Medicina).

\section{COMENTARIO}

Los médicos publicamos para compartir nuestros conocimientos y experiencias. Las prerrogativas de esta información implican que tal investigación debe: a) enriquecer el conocimiento y comprensión de una determinada enfermedad; b) presentar resultados de los estudios realizados; c) comunicar nuevos métodos de diagnóstico o tratamiento; d) reflexionar sobre los resultados publicados; e) revisar un tema específico; f) desarrollar un caso clínico; g) mostrar una imagen ilustrativa, y h) externar ideas y opiniones en ensayos literarios sobre un tema específico relacionado con la medicina.

La mayoría de los médicos, con frecuencia, exponemos nuestras experiencias clínicas a través de conferencias o participando en sesiones clínicas. El reto surge cuando se nos solicita expresar esas experiencias por escrito, ya que escribir bien un artículo científico requiere tiempo, estudio y dedicación.

Pese a que existen múltiples revistas médicas en nuestro país, el número de artículos publicados resulta muy escaso en relación con el número de médicos existentes. Los médicos no estamos acostumbrados a escribir, pues en nuestro medio no existe una cultura para publicar $y$, por lo tanto, escribir un artículo con este fin resulta una tarea compleja; de ahí, que la existencia de un comité de publicación que oriente, apoye, corrija de manera constructiva los documentos y supervise desde los tiempos verbales utilizados en cada parte del manuscrito, la construcción gramatical (evitando verborrea) hasta ayudar en el diseño de investigación, por ejemplo, la utilización de estadística o revisar que las referencias bibliográficas estén acordes con lo solicitado por las publicaciones científicas, resulta de gran ayuda, principalmente para aquellos médicos que se inician en la elaboración de un manuscrito para su publicación.

Como parte de las ideas de este comité, se decidió enviar un manuscrito acompañado de un video - situación (a nuestro conocimiento) no efectuada previamente por ninguna revista en México-. Esta idea fue apoyada por el Dr. Raúl Ariza Andraca, Editor de la revista Acta Médica (a quien agradecemos ampliamente), pues se dio a la tarea de buscar la logística para que esta idea fuera posible y, actualmente, se han publicado cinco imágenes en video y cinco más en prensa; todas hasta el momento de médicos del HAL.

La importancia de la información escrita radica en su trascendencia, además, gracias a la comunicación electrónica, está prácticamente al alcance de todos los interesados, quizá limitada en su difusión por el idioma, pues únicamente los hispanoparlantes pueden acceder a la totalidad de los artículos, en tanto que el resto sólo tiene acceso al resumen en idioma inglés o a una traducción (no de la mejor calidad) a través de traductores automatizados.

Tabla 2: 170 artículos editados en 24 publicaciones.

1. Revista Acta Médica Grupo Ángeles

2. Revista de la Facultad de Medicina de la UNAM

3. Revista Cirugía y Cirujanos

4. Obesity Surgery

5. Revista Anestesia de México

6. Revista Ginecología y Obstetricia de México

7. Revista Mexicana de Medicina Física y Rehabilitación

8. Revista Mexicana de Cardiología

9. Revista Médica MD

10. Revista Gastroenterología de México

11. Revista Endoscopia

12. Revista Acta Ortopédica Mexicana

13. International Journal of Critical Care and Emergency Medicine

14. Global Journal of Medical and Clinical Case Reports

15. Revista Atención Familiar UNAM

16. Global J Obes Diabetes Metab Syndrome

17. SMJ General Surgery and Clinical Research

18. Archives of Clinical Gastroenterology

19. Archives of Surgery and Clinical Research

20. Revista Mexicana de Cirugía Endoscópica

21. Revista Oral

22. Revista Medicina Clínica

23. Cardiac and Metabolic Sciense

24. Capítulo en Libro Medicina Interna 
Consideramos que el trabajo del Comité de Publicaciones del HAL ha sido fructífero, pues la meta inicial de ocho manuscritos al año ha sido ampliamente superada con un promedio de 33 manuscritos al año. Asimismo, se logró involucrar (por convicción y no por obligación) a prácticamente $70 \%$ de los médicos de la institución en la realización de artículos, con una producción de 3.18 manuscritos/mes de manera constante a lo largo de tres años, contando con $82 \%$ de ellos ya editados. Los 27 artículos en prensa permitirán dar a conocer a los médicos de la institución en, al menos, siete diferentes revistas durante lo que resta de 2019 y 2020 . Por otra parte, se cuentan con 10 manuscritos elaborados que ya están en valoración por comités editoriales, los cuales, de ser aceptados, incrementarán las posibilidades de cubrir parte de 2021 y, a su vez, esto aumentará el puntaje curricular de los 98 médicos de la institución.

En cuanto a la información vertida en los artículos publicados, estamos satisfechos, ya que, por una parte, las revistas científicas en las que han aparecido cuentan con comités editoriales que evalúan la calidad de los manuscritos; por la otra, al ser examinados por pares, los documentos enviados se han sometido a revisión por expertos en el tema, quienes emiten un juicio, tanto de la calidad de los datos como de la veracidad de las conclusiones.

Respecto a las perspectivas a futuro de este comité, se ha establecido una relación estrecha con el Comité de Investigación y todas las divisiones y departamentos de la institución para valorar propuestas de investigación factibles, así como la redacción de los protocolos respectivos, con la intención de promover un mayor número de artículos originales. Al mismo tiempo, se busca mantener los números alcanzados en cuanto a la producción de manuscritos de artículos de revisión, de casos clínicos, imágenes en medicina e imágenes en video. La tarea es un reto que requiere mantener e incrementar el esfuerzo y la conjunción multidisciplinaria en un ambiente cordial, que ha sido la característica de este comité.

Consideramos que el médico que escribe y publica es un mejor médico, amén de trascender al dejar algo por escrito y cumplir (como lo establece el Dr. Ruy Pérez Tamayo) con las tres obligaciones que todo médico debe desempeñar en la medida de sus posibilidades: "Cuidar la salud y combatir la enfermedad, compartir sus conocimientos con todo aquél que pueda beneficiarse de ellos (qué mejor que a través de la publicación) y contribuir a enriquecerlos por medio de la investigación médica".

Por último, como coordinador del comité de publicaciones del HAL puedo mencionar que se han sembrado ideas en las que se trabajaron arduamente $y$, habiendo cumplido el ciclo que nos correspondió a cargo de su coordinación, entregamos cuentas, aunque - ciertamente- no considero que sea el indicado para juzgar si los resultados son buenos o no. Sin embargo, el camino está trazado, al igual que las pautas de trabajo en la búsqueda de la excelencia, deseando fervientemente el mayor de los éxitos al próximo coordinador, ya que todo es perfectible. 